\title{
Janus Face Aspect of All-cis 1,2,3,4,5,6-Hexafluorocyclohexane Dic- tates Remarkable Anion and Cation Interactions In the Gas Phase.
}

\author{
Blake E. Ziegler', Michael Lecours'1, Rick A. Marta'1, Joshua Featherstone', Eric Fillion', W. Scott \\ Hopkins ${ }^{1}$, Vincent Steinmetz ${ }^{2}$, Neil S. Keddie ${ }^{3}$, David O’Hagan ${ }^{\star 3}$ and Terrance B. McMahon ${ }^{\star 1}$
}

${ }^{1}$ Department of Chemistry, University of Waterloo, Waterloo, Ontario, Canada N2L $3 \mathrm{G}_{1}{ }^{2}$ Laboratoire Chimie PhysiqueCLIO, Bâtiment 201, Campus Universitaire d'Orsay, Orsay France, $91405 ;{ }^{3}$ EastCHEM School of Chemistry, University of St. Andrews, North Haugh, St. Andrews KY16 9ST, UK.

\begin{abstract}
Experiments have been carried out in which electrospray ionization has been used to generate ionic complexes of all-cis 1,2,3,4,5,6 hexafluorocyclohexane. These complexes were subsequently mass isolated in a quadrupole ion trap mass spectrometer and then irradiated by the tunable infrared output of a free electron laser in the $800-1600 \mathrm{~cm}^{-1}$ range. From the frequency dependence of the fragmentation of the complexes, vibrational signatures of the complexes were obtained. Computational work carried out in parallel reveals that the complexes formed are very strongly bound and are among the most strongly bound complexes of $\mathrm{Na}^{+}$and $\mathrm{Cl}^{-}$ever observed with molecular species. The dipole moment calculated for the heaxafluorocyclohexane is very large $(\sim 7 \mathrm{D})$ and it appears that the bonding in each of the complexes has a significant electrostatic contribution.
\end{abstract}

A detailed knowledge of the nature of the interaction of ions with molecules in the gas phase is especially useful to understand the forces which drive molecular structure and energetics in ionic complexes. Previous work from this laboratory has provided considerable data on the energetics of interaction between ions and neutral molecules. ${ }^{1}$ From these data, an understanding has emerged of the importance of gas phase acidity and basicity of the relevant binding sites leading to covalent binding as well the role of polarizability, and dipole and quadrupole moments for electrostatic binding. For example, an examination of $\mathrm{Na}^{+}$binding energetics to a series of molecules with a range of functionality and heteroatoms reveals a better correlation with dipole moment than with gas phase proton basicity, thus demonstrating the importance of the electrostatic interactions in such complexes. ${ }^{2}$ Similarly, an examination of the binding energetics of chloride ion to a series of $n$ - and cyclo-alkanes has shown a very good correlation with the polarizability of the alkane with the exception that the cyclo-alkanes exhibit a slightly higher binding enthalpy to chloride than the corresponding n-alkane, despite the fact that they have a slightly lower polarizabilty. This can be seen to be due to the somewhat closer approach possible for the total of the individual $\mathrm{C}-\mathrm{H} \cdot \cdots \mathrm{Cl}^{-}$interactions in the cycloalkanes. ${ }^{3}$ In the study of chloride ions bound to alkanes, experimental and computational energetics were in excellent agreement. Lisy and coworkers have also carried out studies of $\mathrm{Li}^{+}, \mathrm{Na}^{+}$and $\mathrm{K}^{+}$bound to cyclohexane in which vibrational spectra were obtained in the $\mathrm{C}-\mathrm{H}$ stretching region and these were compared to computed spectra. ${ }^{4}$ Somewhat surprisingly, the computational work supports assignment of the structures as involving two axial and one equatorial hydrogen rather than three axial hydrogens. Interestingly, the computed binding energy for $\mathrm{Na}^{+}$ with cyclohexane is essentially identical to that computed for $\mathrm{Cl}^{-}$which is very well reproduced by an ion-induced dipole potential.

Prior studies of halide ions binding to a variety of molecules had also shown, not surprisingly, that substitution of hydrogen by an electronegative substituent gave rise to a significant increase in the binding enthalpy. For example, the binding enthalpy of $\mathrm{Cl}^{-}$to acetone has been determined as $\sim 58 \mathrm{kJmol}^{-1}$. Substitution of fluorine for hydrogen, for example in 1,1,3,3 tetrafluoroacetone results in an increase of roughly $30 \mathrm{~kJ} \mathrm{~mol}^{-1}$ in binding enthalpy. ${ }^{6}$ Moreover, in the fluorinated acetone case, bidentate binding occurs. With this consideration in hand, when the studies of $\mathrm{Cl}^{-}$binding to cyclohexane had been carried out, it had been deemed to be of interest to carry out an experiment in which hydrogen was symmetrically substituted by fluorine in order to appreciably enhance the binding energy. Unfortunately, at that 
time, such compounds were not readily available. Most recently however, O'Hagan and co-workers demonstrated the synthesis of all-cis 1,2,3,4,5,6 hexafluorocyclohexane, 1 , which can be considered to be the epitome of the type of compound sought in order to enhance halide ion binding in cyclohexanes. ${ }^{8}$ The orientation of the fluorine atoms in 1 entails a 1,3,5 tri-axial orientation and a 2,4,6 tri-equatorial orientation such that the molecule can be considered to have a fluorine face as well as a hydrogen face. Accompanying computational work ${ }^{8}$ yielded a dipole moment of $\sim 6.2 \mathrm{D}$ for $\mathbf{1}$, leading to the expectation that the binding of anions should be substantially enhanced at the hydrogen face of the molecule. Moreover, it was deemed likely that the binding of cations to the fluorine face of the molecule would be realized.

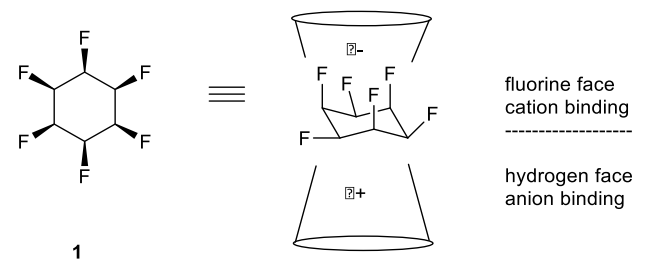

Figure 1. Structures and two faced Janus polarity of $\mathbf{1}$

In order to examine these possibilities, a combined experimental and computational approach was undertaken in which the energetics of binding of both sodium and chloride ions to $\mathbf{1}$, was determined. This also gave detailed information for the structures and vibrational spectra of the ion-neutral molecule adducts which, in the latter case, could be compared to infrared multiple photon dissociation (IRMPD) spectra obtained for these adducts at the CLIO free electron facility in Orsay, France. ${ }^{9}$ Briefly, ions of interest were generated by electrospray ionization and subsequently trapped in a Bruker Esquire ion trap mass spectrometer where they were irradiated by the output of the free electron laser (typically for $150 \mathrm{~ms}$.), which was scanned from $800-1800 \mathrm{~cm}^{-1}$. In each of the $\mathrm{Na}^{+}$and $\mathrm{Cl}^{-}$cases it was possible to generate both the mono-and di- coordinated adducts with $\mathbf{1}$. The photo-products resulting from the IRMPD process involved loss of either 1 or 2 molecules of 1 to generate either the bare ion or the ion coordinated to $\mathbf{1}$.

To gain an understanding of the strength of binding in these adducts, the thermochemistry of reactions 1-4 was calculated using the Gaussian o9 program package ${ }^{10}$ in which geometry optimizations were carried out at the B3LYP level of theory with a $6-311+G(d, p)$ basis set followed by single point calculations of energies at the $\mathrm{MP}_{2}$ (full)/6-311+G(2d,2p) level of theory. In the case of sodium cation and adducts containing sodium cation, the single point energy calculations employed the $\mathrm{MP}$ (full)/aug-cc-
pCVTZ on sodium. ${ }^{2 \mathrm{C}}$ The results for energetics of interaction from the computational analysis are given in Table 1 . In the cases of both positive ion and negative ion complexes, the addition of the second molecule of $\mathbf{1}$ is less favourable than the first, as expected is such systems."

The magnitudes of the binding enthalpies in each case are impressively large. Some of the strongest molecular binding to $\mathrm{Na}^{+}$is that found for amino acids and the data for the complexes investigated here have binding enthalpies comparable to those of the smaller aliphatic amino acids. The only compounds found to exceed significantly the magnitude observed for $\mathrm{Na}^{+}$binding to $\mathbf{1}$ are polyethers such as diglyme, 12-crown-4, 12-crown-5 and 18-crown-6. ${ }^{11,12}$

Table 1. Energetics of Association Reactions

$$
\begin{aligned}
& \mathrm{Na}^{+}+\mathrm{C}_{6} \mathrm{H}_{6} \mathrm{~F}_{6} \rightarrow\left[\mathrm{C}_{6} \mathrm{H}_{6} \mathrm{~F}_{6}\right] \mathrm{Na}^{+} \\
& {\left[\mathrm{C}_{6} \mathrm{H}_{6} \mathrm{~F}_{6}\right] \mathrm{Na}^{+}+\mathrm{C}_{6} \mathrm{H}_{6} \mathrm{~F}_{6} \rightarrow\left[\mathrm{C}_{6} \mathrm{H}_{6} \mathrm{~F}_{6}\right]_{2} \mathrm{Na}^{+}} \\
& \mathrm{Cl}^{-}+\mathrm{C}_{6} \mathrm{H}_{6} \mathrm{~F}_{6} \rightarrow\left[\mathrm{C}_{6} \mathrm{H}_{6} \mathrm{~F}_{6}\right] \mathrm{Cl}^{-} \\
& {\left[\mathrm{C}_{6} \mathrm{H}_{6} \mathrm{~F}_{6}\right] \mathrm{Cl}^{-}+\mathrm{C}_{6} \mathrm{H}_{6} \mathrm{~F}_{6} \rightarrow\left[\mathrm{C}_{6} \mathrm{H}_{6} \mathrm{~F}_{6}\right]_{2} \mathrm{Cl}^{-}}
\end{aligned}
$$

$\begin{array}{cccc}\text { Eqn } & \begin{array}{c}\Delta \mathrm{H}^{\mathrm{o}}{ }_{298} \mathrm{~kJ} \\ \mathrm{~mol}^{-1}\end{array} & \begin{array}{c}\mathrm{S}^{\mathrm{o}}{ }^{198} \mathrm{~J} \mathrm{~mol}^{-1} \\ 1\end{array} \mathrm{~K}^{-1} & \Delta \mathrm{G}^{\mathrm{o}}{ }_{298} \mathrm{~kJ} \mathrm{~mol}^{-1} \\ 2 & -175.9 & -116.3 & -141.3 \\ 3 & -145.4 & -132.9 & -105.8 \\ 4 & -156.5 & -97.2 & -127.5 \\ & -114.5 & -112.5 & -81.0\end{array}$

Similarly, the binding enthalpy for the second molecule of $\mathbf{1}$ is among the largest ever reported for binding of two molecules to sodium. ${ }^{11,13}$ The binding of chloride ion to $\mathbf{1}$ is also found to be very strong. The binding enthalpy of $156.5 \mathrm{~kJ} \mathrm{~mol}^{-1}$ is comparable to that found for very strong gas phase Brønsted and Lewis acid species. For example, the largest molecular binding enthapy to $\mathrm{Cl}^{-}$found in the NIST database is that for $p$-cyanophenol ${ }^{11,14}$ at $148 \mathrm{~kJ} \mathrm{~mol}^{-1}$. Similarly, the binding enthalpies of chloride ion to Lewis acids such as $\mathrm{BF}_{3}\left(109 \mathrm{~kJ} \mathrm{~mol}^{-1}\right), \mathrm{AsF}_{3}(108 \mathrm{~kJ}$ $\left.\mathrm{mol}^{-1}\right)$ and $\mathrm{SiCl}_{4}\left(101 \mathrm{~kJ} \mathrm{~mol}^{-1}\right)$ are all substantially weaker than that to $1 .{ }^{11,15}$ Thus, $\mathbf{1}$ is a contender for the molecule with the strongest molecular binding to $\mathrm{Cl}^{-}$. Once again very few, if any, second molecule binding enthalpies are stronger than that to 1 . For example, the binding of a second molecule of $\mathrm{HCN}$ to the $\mathrm{Cl}^{-}$ (HCN) complex ${ }^{16}$ is found to be $75 \mathrm{~kJ} \mathrm{~mol}^{-1}$, considerably less than that found here for a second molecule of 1 of $114.5 \mathrm{~kJ} \mathrm{~mol}^{-1}$.

It is also of considerable interest to examine the details of the structures of the complexes formed between $\mathrm{Na}^{+}$and $\mathrm{Cl}^{-}$with 1. Consistent with the decrease in binding enthalpy for the second addition of 1 relative to the first addition to $\mathrm{Na}^{+}$, it can be seen(Table 2, Figure 2) that the contact distance be- 
tween $\mathrm{Na}^{+}$and each of the axial fluorines increases from $2.28 \AA$ in the monomer to $2.34 \AA$ in the dimer. Similarly, the second addition of $\mathbf{1}$ to its monomeric complex with $\mathrm{Cl}^{-}$increases the contact distance between $\mathrm{Cl}^{-}$and the axial hydrogens in the dimer complex from $2.53 \AA$ to $2.60 \AA$. Interestingly, the magnitude of the contact distance changes in the $\mathrm{Na}^{+}$and $\mathrm{Cl}^{-}$complexes are relatively similar (0.06 $\AA$ for $\mathrm{Na}^{+}$ and $0.07 \AA$ for $\mathrm{Cl}^{-}$) while the changes in binding enthalpies are somewhat larger for $\mathrm{Cl}^{-}\left(42 \mathrm{~kJ} \mathrm{~mol}^{-1}\right)$ than for $\mathrm{Na}^{+}\left(30 \mathrm{~kJ} \mathrm{~mol}^{-1}\right)$.

With respect to other geometric parameters within these complexes, it is of interest to note the relative lack of changes in covalent bond distances within the 1 moieties which accompany the complexation with these ions, despite the very strong energies of binding. As can be seen from Table 2 there is no change in bond distance greater than $0.04 \AA$. The largest

Table 2. Calculated Covalent Bond Distances $(\AA)$

$\begin{array}{cccccc} & 1 & \mathrm{MNa}^{+} & \mathrm{M}_{2} \mathrm{Na}^{+} & \mathrm{MCl}^{-} & \mathrm{M}_{2} \mathrm{Cl}^{-} \\ \mathrm{C}-\mathrm{C} & 1.532 & 1.530 & 1.530 & 1.526 & 1.527 \\ \mathrm{C}-\mathrm{H}_{\mathrm{ax}} & 1.098 & 1.097 & 1.097 & 1.099 & 1.097 \\ \mathrm{C}-\mathrm{H}_{\mathrm{eq}} & 1.094 & 1.090 & 1.091 & 1.093 & 1.093 \\ \mathrm{C}-\mathrm{F}_{\mathrm{ax}} & 1.380 & 1.418 & 1.409 & 1.396 & 1.392 \\ \mathrm{C}-\mathrm{F}_{\mathrm{eq}} & 1.384 & 1.377 & 1.378 & 1.400 & 1.397 \\ \mathrm{X}-\mathrm{H} / \mathrm{F} & & 2.282 & 2.341 & 2.532 & 2.604\end{array}$

changes occur in the axial $\mathrm{C}-\mathrm{F}$ bond distances with a lengthening of $0.04 \AA$ and $0.03 \AA$ in the $\mathrm{Na}^{+}$complexes and 0.01 to $0.02 \AA$ in the $\mathrm{Cl}^{-}$complexes. Relative to isolated $\mathbf{1}$, a very small contraction occurs in the equatorial $\mathrm{C}-\mathrm{F}$ bonds in the $\mathrm{Na}^{+}$complexes of $\sim 0.007$ $\AA$ and a minor lengthening in the $\mathrm{Cl}^{-}$complexes of 0.016 and $0.013 \AA$. The fact that the covalent bond system of 1 remains essentially unchanged in the complexation process suggests that the interaction of the ions with the molecule via the axial fluorine or hydrogen atoms is largely electrostatic in origin, involving ion-dipole and ion-induced dipole potentials. A calculation of the ion-induced dipole interaction between $\mathrm{Cl}^{-}$and cyclohexane gives, within experimental error, exactly the experimentally determined value of $40 \mathrm{~kJ} \mathrm{~mol}^{-1}$. Given the very large dipole moment of 1 and the distances of approach of these monoatomic ions to the molecule, it is likely that the charge dipole and charge induced dipole interactions contribute substantially to the overall energetics of interaction.

Vibrational frequencies for the ion-molecule adducts obtained from the IRMPD experiments have been compared to computed spectra for the same adducts, as well as to the computed spectrum of $\mathbf{1}$ itself. One such spectrum, for the $\left[\mathrm{C}_{6} \mathrm{H}_{6} \mathrm{~F}_{6}\right]_{2} \mathrm{Cl}^{-}$spe- cies, is shown in Figure 3, where the red lines represent the computed frequencies (with a scaling factor of 0.986 ) and relative intensities.
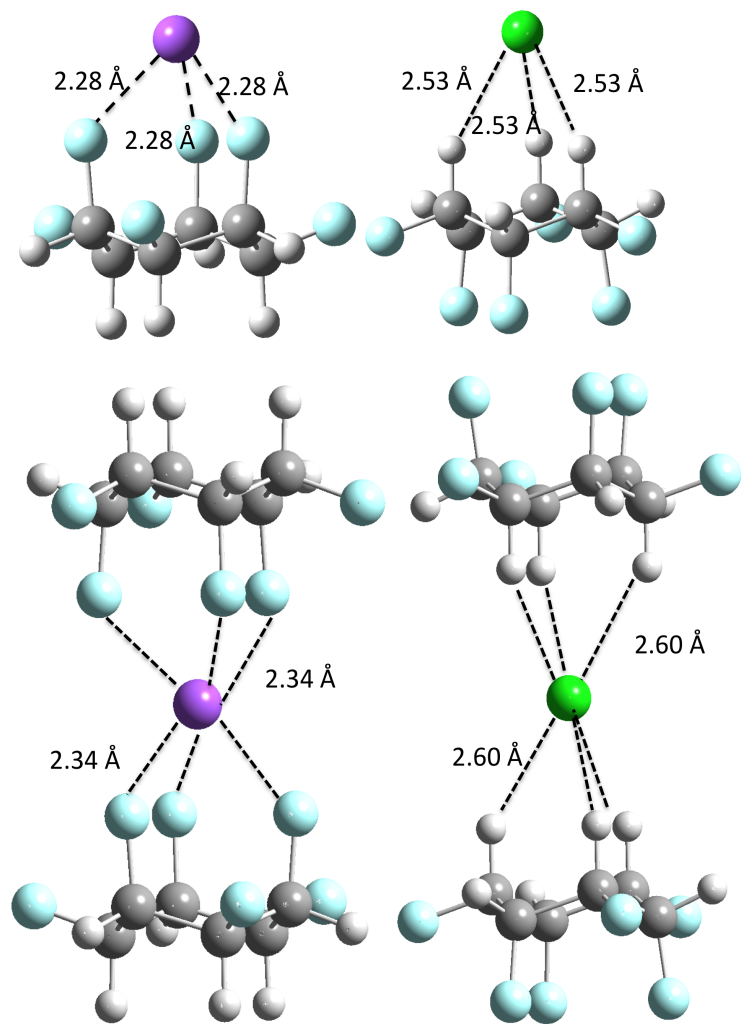

Figure 2. Structures of the $\mathrm{Na}^{+}$and $\mathrm{Cl}^{-}$ions coordinated to one and two molecules of $\mathbf{1}$.

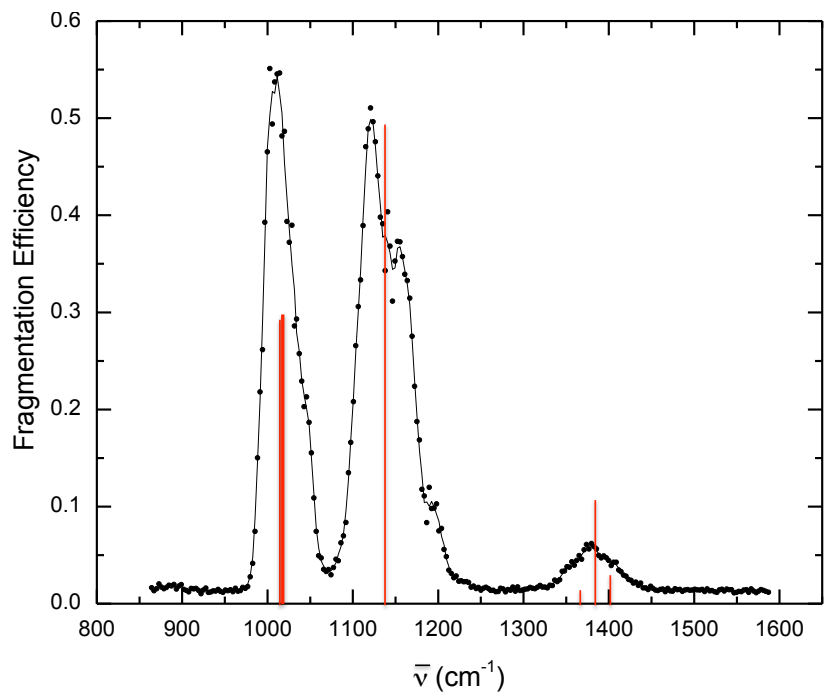

Figure 3. IRMPD spectrum of the complex of $\mathrm{Cl}^{-}$bound to two molecules of $\mathbf{1}$. The black points represent the actual experimental data points and the red lines the computed vibrational frequencies (scaled by 0.986).

This spectrum, and in fact all of the IRMPD spectra obtained for the extensive series of ionic adducts examined, exhibit a very strong resemblance to the computed spectrum of isolated monomeric 1 with some minor shifts depending upon the ion involved. The broadening of the peaks in the $1000-1100 \mathrm{~cm}^{-1}$ and $1100-1200 \mathrm{~cm}^{-1}$ ranges, as well as the shoulder on the 
latter feature, suggests that there may in fact be two species present with this composition. Additional computational work has revealed a structure in which a neutral dimer of $\mathbf{1}$ is bound to the chloride ion which lies $15 \mathrm{~kJ} \mathrm{~mol}^{-1}$ higher in energy that the species described above. This structure is shown in the Supporting Information. Given the more favorable energetics of the structure shown in Figure 2, it is likely that this species dominates in the spectrum. The computed vibrational spectrum of $\mathbf{1}$, as well as those of the two possible $\left[\mathrm{C}_{6} \mathrm{H}_{6} \mathrm{~F}_{6}\right]_{2} \mathrm{Cl}^{-}$species described above, are also provided in the Supporting Information.

In the cases of the four ionic species discussed above, the most intense modes involve vibrations which are substantially C-F stretch in character and, significantly, the primarily axial and equatorial C-F stretches occur at different frequencies. In Table 3, the computed values for the modes of highest intensity are summarized for the isolated molecule and each of the adducts of $\mathbf{1}$. Consistent with the slight shortening of the $\mathrm{C}-\mathrm{F}_{\mathrm{eq}}$ bonds in the two sodium cation complexes, the frequency of the $\mathrm{C}^{-} \mathrm{F}_{\text {eq }}$ stretch vibration increases slightly. Similarly, those same bonds for the chloride complexes are lengthened somewhat and the corresponding frequencies are lower relative to the isolated molecule.

In analogous fashion, the axial C-F mode frequencies follow the slight shifts in equilibrium bond distances among the set of complexes described here where the bond distances in the ionic complexes are each somewhat longer and the corresponding frequencies are somewhat lower.

Table 3: Computed Vibrational Frequencies (scaled by 0.986) $\left(\mathrm{cm}^{-1}\right)$

$\begin{array}{lccc}\text { Species } & \mathrm{C}-\mathrm{F}_{\mathrm{eq}} & \mathrm{C}-\mathrm{F}_{\mathrm{ax}} & \mathrm{C}-\mathrm{H}_{\text {wag }} \\ \text { All-cis- } \mathrm{C}_{6} \mathrm{H}_{6} \mathrm{~F}_{6} & 1039 & 790,1150 & 1363,1355 \\ {\left[\text { cis- } \mathrm{C}_{6} \mathrm{H}_{6} \mathrm{~F}_{6}\right] \mathrm{Na}^{+}} & 1050 & 767,1055 & 1362 \\ {\left[\text { cis- } \mathrm{C}_{6} \mathrm{H}_{6} \mathrm{~F}_{6}\right]_{2} \mathrm{Na}^{+}} & 1048 & 1065 & 1363 \\ {\left[\text { cis- } \mathrm{C}_{6} \mathrm{H}_{6} \mathrm{~F}_{6}\right] \mathrm{Cl}^{-}} & 999 & 774,1107 & 1347,1369 \\ {\left[\text { cis- } \mathrm{C}_{6} \mathrm{H}_{6} \mathrm{~F}_{6}\right]_{2} \mathrm{Cl}^{-}} & 1027 & 779,1137^{17} & 1352,1367\end{array}$

The analogous changes for axial and equatorial $\mathrm{C}-\mathrm{H}$ stretching frequencies could not be probed experimentally due to the limited frequency range accessible with the FEL. However, computationally, the expected result is seen with variations less than $20 \mathrm{~cm}^{-1}$ relative to 1, consistent with the minimal changes observed in $\mathrm{C}-\mathrm{H}$ bond distances.

Analogous IRMPD experiments have been carried out for each of the atomic alkali cations and halide anions with both one and two molecules of 1 with, for the most part, similar vibrational spectra observed. Computational work is currently underway to explore further the structures and energetics of these complexes. The one notable exception to this commonality for atomic anion complexes is that for the fluoride ion where considerably more structure is observed in the $900-1200 \mathrm{~cm}^{-1}$ region of the IRMPD spectrum. It seems clear that, even though the masses of the adducts observed are consistent with formation of the analogous anionic association adducts, either chemical reaction or alternative binding modes are being observed here. Gas phase ion-molecule reactions of fluoride ions with fluoroalkanes are known to be rich, involving proton abstraction and $\mathrm{FHF}^{-}$formation accompanied by hydrogen bond formation to $\mathrm{C}-\mathrm{H}$ bonds. ${ }^{18}$ Potential complexes resulting from addition of $\mathrm{F}^{-}$to $\mathbf{1}$ are also the subject of ongoing experimental and computational investigation. As well, a number of complexes involving polyatomic anions have also been the subject of the IRMPD studies, including $\mathrm{BF}_{4}{ }^{-} \mathrm{HCO}_{2}{ }^{-}$and $\mathrm{B}_{12} \mathrm{~F}_{12}{ }^{2-}$.

In summary, all-cis hexafluorocyclohexane displays an extraordinary propensity to bind both cations and anions. This is a consequence of its differentially polarized faces which suggests that $\mathbf{1}$, or analogous derivatives, has potential to act as a complexation motif to associate with or deliver cations and anions in both polar and non-polar media and in supramolecular chemistry.

\section{Acknowledgements}

Generous financial support of this work by in the form of NSERC (Canada) Discovery Grants to EF, WSH, and TBM and an EPSRC (UK) responsive mode grant to DO'H and NSK is gratefully acknowledged. The authors are also very grateful for the award of FEL beam time by and the valuable assistance of the staff of the Centre Laser Infrarouge d'Orsay. The high performance computing time and staff support of the SHARCNET consortium of Compute Canada is also gratefully acknowledged.

References.

1. Wu, R.; McMahon, T. B. Mass Spectrom. Rev. 2009, 28, 546.

2. (a) Hoyau, S.; Norrman, K.; McMahon, T. B.; Ohanessian, G. J. Am. Chem. Soc. 1999, 121, 8864. (b) McMahon, T. B.; Ohanessian, G. Chem. Eur J. 20oo, 6, 2931. (c) Marta, R. A.; Wu, R. H.; Eldridge, K. R.; Martens, J. K. McMahon, T. B. Int. J. Mass Spectrom. 2010, 297, 76 .

3. Ziegler, B. E.; Gamble, T.; Li, C.; McMahon, T. B. J. Phys. Chem. A. 2013, 117, 5785 .

4. (a) Patwari, G. N.; Lisy, J. M. J. Phys. Chem. A. 2007, 111, 7585. (b) Sibert, E. L.; Tabor, D. P. Lisy, J. M. J. Phys. Chem. A. 2015, 119, 10293.

5. (a) Sieck, L. W.; J. Phys. Chem. 1985, 89, 5552. (b) Bogdanov, B.; McMahon, T. B. Int. J. Mass Spectrom. 2002, 219, 593.

6. Larson, J.; McMahon, T. B. J. Phys. Chem. 1984, 88, 1083.

7. Bogdanov, B.; Lee, H. J. S.; McMahon, T. B. Int. J. Mass Spectrom. 2001, 210, 387 . 
8. (a) Keddie, N. S.; Slawin, A. M. Z.; Lebl, T.; Philp, D.; O'Hagan, D. Nature Chem. 2015, 7, 483. (b) Cormanich, R. A.; Keddie, N. S.; Rittner, R.; O'Hagan, D.; Buhl; M. Phys. Chem. Chem. Phys. 2015, 17, 29475.

9. Sinha, R. K.; Nicol, E.; Steinmetz, V.; Maître, P. J. Am. Soc. Mass Spectrom. 2010, 21, 758.

10. Gaussian 09, Revision E.01, Frisch, M. J.; Trucks, G. W.; Schlegel, H. B.; Scuseria, G. E.; Robb, M. A.; Cheeseman, J. R.; Scalmani, G.; Barone, V.; Mennucci, B.; Petersson, G. A.; Nakatsuji, H.; Caricato, M.; Li, X.; Hratchian, H. P.; Izmaylov, A. F.; Bloino, J.; Zheng, G.; Sonnenberg, J. L.; Hada, M.; Ehara, M.; Toyota, K.; Fukuda, R.; Hasegawa, J.; Ishida, M.; Nakajima, T.; Honda, Y.; Kitao, O.; Nakai, H.; Vreven, T.; Montgomery, J. A., Jr.; Peralta, J. E.; Ogliaro, F.; Bearpark, M.; Heyd, J. J.; Brothers, E.; Kudin, K. N.; Staroverov, V. N.; Kobayashi, R.; Normand, J.; Raghavachari, K.; Rendell, A.; Burant, J. C.; Iyengar, S. S.; Tomasi, J.; Cossi, M.; Rega, N.; Millam, J. M.; Klene, M.; Knox, J. E.; Cross, J. B.; Bakken, V.; Adamo, C.; Jaramillo, J.; Gomperts, R.; Stratmann, R. E.; Yazyev, O.; Austin, A. J.; Cammi, R.; Pomelli, C.; Ochterski, J. W.; Martin, R. L.; Morokuma, K.; Zakrzewski, V. G.; Voth, G. A.; Salvador, P.; Dannenberg, J. J.; Dapprich, S.; Daniels, A. D.; Farkas, Ö.; Foresman, J. B.; Ortiz, J. V.; Cioslowski, J.; Fox, D. J. Gaussian, Inc., Wallingford CT, 2009.

11. P. J. Linstrom and W. G. Mallard, Eds., NIST Chemistry WebBook, NIST Standard Reference Database Number 69, National Institute of Standards and Technology, Gaithersburg MD, 20899, http://webbook.nist.gov.

12. (a) Rodgers, M. T.; Armentrout, P. B. Mass Spectrom. Rev. 2000,19 215. (b) More, M. B.; Ray D.; Armentrout, P. B. J. Am. Chem. Soc. 1999, 121, 417. (c) More, M. B.; Ray D.; Armentrout, P. B. J. Phys. Chem. A. 1997, 101, 7007.

13. Tsirlina, E. A.; Gusarov, A. V.; Gorokhov, L. N. High Temp., 1986, 4, 1064.

14. Paul, G. J. C.; Kebarle, P. Can. J. Chem. 1990, 68, 2070.

15. Larson, J. W.; McMahon, T. B. J. Am. Chem. Soc. 1985, 107, 766

16. Meot-Ner, M.; Cybulski, S. M.; Scheiner, S.; Liebman, J. J. Phys. Chem. 1988, 92, 2378.

17. The shoulder on this peak in Figure 3 may be due to contributions from either a small amount of a twist boat conformer of $\mathbf{1}$ in this complex or, alternatively, to a small amount of binding of Cl- to neutral dimer of 1 . (See Supporting Information).

18. Roy, M.; McMahon, T. B. Can. J. Chem. 1985, 63, 708. 